\title{
Proactive versus Reactive Therapeutic Drug Monitoring: Why, When, and How?
}

\author{
Manar Shmais $^{\mathrm{a}}$ Miguel Regueiro ${ }^{\mathrm{b}}$ Jana G. Hashash ${ }^{\mathrm{a}, \mathrm{c}}$ \\ aDivision of Gastroenterology and Hepatology, American University of Beirut, Beirut, Lebanon; \\ ${ }^{b}$ Division of Gastroenterology, Hepatology, and Nutrition, Cleveland Clinic Foundation, Cleveland, OH, USA; \\ 'Division of Gastroenterology and Hepatology, Inflammatory Bowel Disease Center, Mayo Clinic, \\ Jacksonville, FL, USA
}

\section{Keywords}

Therapeutic drug monitoring $\cdot$ Trough level $\cdot$ Anti-drugantibody $\cdot$ Inflammatory bowel disease $\cdot$ Biological

\begin{abstract}
Background: Up to a third of inflammatory bowel disease) patients show primary nonresponse to antitumor necrosis factor (anti-TNF) biological therapy, and of those who respond, up to $40 \%$ develop secondary loss of response (LOR). Therapeutic drug monitoring (TDM) plays a crucial role in assessing patients with LOR to guide therapy by giving more of the drug or switching to a different biological agent. Although reactive TDM is suggested or recommended by the majority of gastroenterology associations, proactive TDM seems to be more controversial. Summary: In this article, we discuss the updated guidelines on TDM and will also discuss the available data supporting proactive and reactive TDM in patients with Crohn's disease and those with ulcerative colitis using the different available biological agents. Key Messages: Therapeutic drug monitoring (TDM) is a valuable tool to aid in inflammatory bowel disease (IBD) therapy optimiza-
\end{abstract}

karger@karger.com www.karger.com/iid

Karger"

BOPEN ACCESS
C 2021 The Author(s)

Published by S. Karger AG, Basel

This is an Open Access article licensed under the Creative Commons Attribution-NonCommercial-4.0 International License (CC BY-NC) (http://www.karger.com/Services/OpenAccessLicense), applicable to the online version of the article only. Usage and distribution for commercial purposes requires written permission. tion. Reactive TDM is widely accepted in IBD patients with suspected loss of response, especially in those receiving antitumor necrosis factor (anti-TNF) agents. Proactive TDM is emerging as a reasonable approach to patients initiated on anti-TNF therapy, specifically infliximab and, to some extent, adalimumab, particularly for patients with severe ulcerative colitis and fistulizing Crohn's disease. Similarly, TDM may play a role in patients considering de-escalation from combination therapy. To date, proactive TDM is not widely applied to ustekinumab and vedolizumab and more data are required before this becomes part of clinical practice.

(c) 2021 The Author(s)
Published by S. Karger AG, Basel

\section{Introduction}

Despite the expanding therapeutic armamentarium for patients with inflammatory bowel disease (IBD), many patients continue to struggle with primary nonresponse (PNR) and secondary loss of response (LOR) to the different available biological agents. As a result, therapeutic drug monitoring (TDM) remains a very impor- 
tant tool in optimizing the management of patients with IBD and subsequently improving their outcomes [1]. In the past, TDM was only used for thiopurines, but more recently, it has become readily available for all the different biological agents approved for the management of IBD. The question that is yet to be answered is whether TDM should be ordered when patients are unwell, regardless of the biological they are receiving, as a reactive measurement, or if proactive monitoring should be implemented as well.

In reactive TDM, serum drug level and presence of anti-drug antibodies (ADA) are measured in patients receiving a biological agent, in response to evidence of active disease that is confirmed with objective evidence via endoscopy, biochemically, or radiographically [2]. Reactive TDM allows physicians to determine whether a patient has developed ADA to the biological they are receiving, if the drug level is suboptimal, or if the patient has adequate drug levels. Interpretation of these results guide managements which could be to increase the dose of the biologic, narrow the interval, add an immunomodulator, or switch to a different biological, of the same or different class. In the recent years, some experts have encouraged the practice of proactive TDM in patients receiving antitumor necrosis factor (anti-TNF) agents, where drug levels are measured in an empirical manner to ensure optimal drug levels and potentially decrease the risk of ADA development and subsequent LOR. Proactive TDM can be performed either during the induction or post-induction periods or during the maintenance phase in asymptomatic patients who have no objective/ endoscopic evidence of active disease. This review will cover the updated guidelines on TDM and will discuss the available data supporting proactive and reactive TDM in patients with Crohn's disease (CD) and those with ulcerative colitis (UC) using the different biological agents.

\section{Available Assays}

Different commercial assays exist to measure serum drug and ADA levels. The 3 most commonly utilized assay formats are the enzyme-linked immunosorbent assay (ELISA), radioimmunoassay (RIA), and homogenous mobility shift assay (HMSA). Measurement of trough concentrations is comparable between the assays, with acceptable accuracy, specificity, and reproducibility. However, the reporting of $\mathrm{ADA}$ is variable between these commercial assays and there is no standardized reporting

Proactive versus Reactive TDM for these values. There are known advantages for measuring ADA in a fluid phase system (RIA and HMSA) over the solid phase system (ELISA) since fluid phase techniques can detect low-affinity ADA, in contrast to the solid phase assays [3]. One of the major limitations in using ELISA is the inability to detect ADA in the presence of drug, as $\mathrm{ADA}$ is bound in ADA-drug complexes that evade detection, even if the amount of drug is $1 \mu \mathrm{g} / \mathrm{mL}$. However using HMSA, the ability to measure ADA is preserved up to serum drug titer of $60 \mu \mathrm{g} / \mathrm{mL}$ [4]. Therefore, differences in sensitivity are mainly attributed to the interference of drug in the detection of ADA. It is advised to utilize the same assay per patient when checking for trough concentrations and ADA.

\section{Interpretation of Drug Levels}

Four scenarios can exist when TDM is checked [5-9]. Approximately half of the patients (50\%) undergoing reactive TDM have undetectable/subtherapeutic drug trough level and undetectable ADAs. This situation is referred to as nonimmune-mediated pharmacokinetic failure and likely represents rapid drug clearance in the setting of high inflammatory burden or suboptimal weightbased dosing. This is the most favorable TDM result since administration of more drugs should fix the problem; either by increasing the dose or narrowing the frequency of drug administration. Around $20 \%$ of patients undergoing reactive TDM will have undetectable/subtherapeutic drug trough level but detectable ADAs that are referred to as "neutralizing" ADAs [5]. In this scenario of immune-mediated pharmacokinetic failure, if the ADA titers are low, then trial to overcome these neutralizing drug antibodies by adding an immunomodulator agent and giving more of that same biological agent may be considered. In case the ADA titers are high, then a switch of biological needs to be performed; and the decision of in-class or out-of-class switch depends on the patient's initial response to the drug. In cases where the trough level is therapeutic, regardless of presence or absence of ADAs, mechanistic failure exists and patients should be switched to a different biological out of class. A quarter of patients (25\%) undergoing reactive TDM will have mechanistic failure with therapeutic drug trough levels and absent/undetectable ADAs, while $5 \%$ of patients undergoing reactive TDM, will have a therapeutic drug level and detectable ADAs. In the latter situation, in addition to switching out of class, it is recommended to add an immunomodulator agent [5]. 
The American Gastroenterological Association recently published suggested target drug trough concentrations based on cross-sectional studies of IBD patients receiving maintenance therapy to be used as a guide when applying reactive TDM [5]. For infliximab, the suggested trough concentration was $\geq 5 \mu \mathrm{g} / \mathrm{mL}$, while for adalimumab, it was $\geq 7.5 \mu \mathrm{g} / \mathrm{mL}$, and for certolizumab pegol, it was $\geq 20 \mu \mathrm{g} / \mathrm{mL}$. It is important to interpret these results with caution since the studies used to extract these data were variable utilizing different assays, heterogeneous patient sample, and were not designed to evaluate patients who had secondary LOR. To date, optimal trough concentrations for induction are lacking.

\section{Available Guidelines}

Different societies have set a number of recommendations regarding TDM use, despite the absence of high quality of evidence on this topic. In a conditional recommendation supported by very low quality of evidence, the AGA suggests reactive TDM in adults with active IBD on anti-TNF therapy to guide treatment changes. No recommendation was made regarding the use of proactive TDM in quiescent IBD patients on anti-TNF treatment, based on a knowledge gap on this subject [10]. No TDM recommendations were made by the AGA with regards to nonanti-TNF biologicals. However, in an expert opinion, a recommendation was made for reactive TDM for vedolizumab and ustekinumab in patients showing signs of primary or secondary nonresponse [2]. The American College of Gastroenterology (ACG) suggests the use of reactive TDM in moderately severe UC patients who are experiencing signs of disease relapse. There are no available recommendations regarding proactive TDM [11]. Regarding CD, the ACG makes no clear recommendations, but make a comment to consider reactive TDM in patients displaying evidence of active CD. The European Crohn's and Colitis Organization (ECCO) do not make any recommendations for or against reactive or proactive TDM in CD patients on anti-TNF due to insufficient evidence [12]. The IBD Sydney Organization and the Australian Inflammatory Bowel Diseases Consensus Working Groups, however, recommended reactive TDM in any IBD patient with secondary LOR to guide clinical decision-making, and they advised that proactive TDM should be performed for patients in stable remission only if results are likely to impact clinical management [13]. The British Society of Gastroenterology suggests that patients with LOR have to undergo TDM to guide treatment with an agreement of 97.6\% [14]. For patients who recently start an anti-TNF, assessment 2-4 weeks after completing the loading dose should be performed. This assessment is based on clinical response and blood measures, such as serum drug and ADA concentrations, serum inflammatory markers, fecal biomarkers, or endoscopy [14]. As for the BRIDGe group, this group makes recommendations for anti-TNF and vedolizumab-treated patients who are experiencing PNR or secondary LOR, specifically to exclude presence of ADAs, and provide no guidance on therapeutic drug concentrations [2]. The BRIDGe group also supports proactive TDM at least once during maintenance for patients on all anti-TNFs [2]. The same groups also support proactive TDM in responders after induction of anti-TNF therapy [2].

\section{Proactive or Reactive TDM}

Up to one-third of patients with IBD show PNR to anti-TNF biological therapy and of the responders, 25$40 \%$ of patients develop secondary LOR after 12 months, and $20 \%$ annually thereafter [15-18]. TDM explains why negative therapeutic outcomes are occurring and allow for the identification of patients who will benefit from dose adjustment or those who should switch to a different biological agent. There are more data available on the use of TDM for the anti-TNF agents than the nonanti-TNF biologicals.

\section{Infliximab}

Over $50 \%$ of patients receiving infliximab will eventually lose response to the drug, with an estimated LOR rate of $13 \%$ per year [19]. In patients who display signs and symptoms of secondary LOR, reactive TDM has been shown to be more cost effective than empirical dose escalation in the management of these patients. Additionally, in the same study by Papamichael et al. [20], reactive TDM was associated with better endoscopic outcomes than clinical decision-making alone. In a different multicenter prospective randomized double-blinded controlled study of 122 biological naive adult CD patients, the TAILORIX study demonstrated that increasing the infliximab dose based on a combination of symptoms, biomarkers, and/or TDM did not lead to corticosteroid-free clinical remission at week 54 compared to patients who underwent infliximab dose escalation based on symptoms alone [21].

The post hoc analysis of the TAILORIX study found that infliximab trough concentrations $>23.1 \mathrm{mg} / \mathrm{L}$ at week
Shmais/Regueiro/Hashash 
2 and $>10.0 \mathrm{mg} / \mathrm{L}$ at week 6 were associated with endoscopic remission at week 12 [22]. It was also shown that the use of fecal calprotectin and proactive TDM can guide dose adjustment and increase the rates of endoscopic response and remission during the maintenance period [22]. The post hoc analysis of ACCENT 1, a multicenter, randomized, placebo-controlled study on $\mathrm{CD}$ patients showed that serum infliximab concentration of $>3.5 \mu \mathrm{g} /$ $\mathrm{mL}$ at week 14 was a predictor of durable sustained response during maintenance therapy at a dose of $5 \mathrm{mg} / \mathrm{kg}$ [23].

A retrospective observational study on perianal $\mathrm{CD}$ patients receiving infliximab revealed that infliximab drug levels of $9.25 \mu \mathrm{g} / \mathrm{mL}$ at week 2 and $7.25 \mu \mathrm{g} / \mathrm{mL}$ at week 6 were the best predictors of fistula response [24]. Additionally, high-induction infliximab levels at weeks 2 and 6 were found to be independently associated with fistula response at both weeks 14 and 30 [24]. The PRECISION study was the first prospective randomized trial evaluating clinical benefit from personalized infliximab dosing in IBD patients. In the majority of patients with trough levels $>3 \mu \mathrm{g} / \mathrm{mL}$ dose reduction did not lead to clinical LOR except in CD patients with perianal fistulas suggesting that a trough level of $3 \mu \mathrm{g} / \mathrm{mL}$ is probably insufficient for fistula control [25]. In a pilot observational study, optimization of infliximab ("optimized monotherapy") to a trough concentration of $\geq 5 \mu \mathrm{g} / \mathrm{mL}$ using TDM was reported as an alternative strategy to combination therapy with concomitant immunomodulators in a subset of patients [26].

Reactive TDM was compared with proactive TDM in a simulated cohort study among CD patients receiving maintenance infliximab monotherapy [19]. Patients who underwent proactive TDM every 6 months were found to have higher infliximab concentrations and much lower ADA levels with subsequent less $\mathrm{CD}$ flares and a marginally cost-effective strategy than patients undergoing reactive TDM [19]. In a meta-analysis by Shah et al. [27] that compared proactive TDM with reactive TDM, results favored proactive TDM in order to prevent drug failure, while possibly being a more cost-saving method particularly that de-escalation of drug could be implemented depending on trough levels in the adequate clinical scenario. The evidence supporting these conclusions, however, was deemed to be of very low quality because of significant heterogeneity between the included studies [27].

In a study that included both CD and UC patients, the Trough Concentration Adapted Infliximab Treatment (TAXIT) trial, IBD patients on infliximab maintenance therapy were adjusted, either increased or decreased, to a trough concentration between 3 and $7 \mu \mathrm{g} / \mathrm{mL}$. Among CD patients, significant improvements in clinical remission rates and median C-reactive protein measurements were noted when pre- and post-dose adjustments were compared. These improvements were not noted among UC patients. Patients were then randomized to 2 groups; 1 with drug dose adjustment based on clinical and biological biomarkers and another with concentration based dosing (aiming for trough level between 3 and $7 \mu \mathrm{g} / \mathrm{mL}$ ). After 1-year follow-up, although no further improvement occurred in clinical remission rates, more relapses and higher ADAs were detected in the clinically based group [28].

In a comparative study that also included CD and UC patients, treatment was proactively escalated aiming at a trough level between 3 and $7 \mu \mathrm{g} / \mathrm{mL}$ for CD patients or between 5 and $10 \mu \mathrm{g} / \mathrm{mL}$ for UC patients. Further escalation/de-escalation of treatment based on clinician's discretion was performed. The results showed that proactive TDM is associated with increased rates of mucosal healing and lower rates of surgery and endoscopic inflammation, than a cohort managed without TDM [29]. A new prospective study involving $34 \mathrm{CD}$ and $29 \mathrm{UC}$ patients revealed that intermediate infliximab levels in addition to infliximab peak (week 2) and infliximab trough (week 6) levels were associated with remission at week 30 [30].

\section{Adalimumab}

In the past, adalimumab was presumed to be less immunogenic than the chimeric infliximab because of its fully human structure and subcutaneous administration [31]. However, data showed that immunogenicity significantly affects the outcome of adalimumab therapy in CD patients and that ADA were identified in patients who have no response to adalimumab (odds ratio [OR]: 13.1, confidence interval [CI]: 1.7-99.2; $p=0.006$ ) [31]. In the POETIC study, a prospective observational study including $98 \mathrm{CD}$ patients who were initiated on adalimumab, $32 \%$ developed ADA, at least half of whom (55\%) developed antibodies as early as week 2 , while almost $80 \%$ had ADA by week 14. Compared to ADA to infliximab, rates of ADA to adalimumab over time was significantly lower ( $p=0.01)$ [32].

In a meta-analysis enrolling $459 \mathrm{CD}$ patients, it was found that patients with adalimumab trough levels over $4.85-5.9 \mathrm{mg} / \mathrm{mL}$ were twice more likely to be in remission than patients with a trough level below this cutoff (OR: 2.6, 95\% CI: $1.79-3.77 ; p<0.0001$ ) [33]. In a retrospective cohort study including 116 biological naive CD patients who were started on adalimumab, patients with low-se- 
rum levels at week $4(<8.3 \mu \mathrm{g} / \mathrm{mL})$ were at significantly higher risk of having ADA by week 12 (46.7 vs. 13.0\%, $p$ $=0.009$ ) [34]. This supports that early monitoring of adalimumab serum levels guides dose optimization, may prevent immunogenicity, and influence long-term outcomes.

The relationship between serum adalimumab concentrations and clinical outcomes was assessed in $275 \mathrm{CD}$ patients using data from CLinical Assessment of Adalimumab Safety and Efficacy Studied as Induction Therapy in CD (CLASSIC) I/II. Among patients who achieved clinical remission, the median adalimumab concentrations were significantly higher than in those who did not achieve clinical remission at week 4 of CLASSIC I ( 8.10 vs. $5.05 \mathrm{mg} / \mathrm{mL}, p<0.05$ ) [35]. In a retrospective study of 43 patients with moderate to severe UC who were initiated on adalimumab, it was found that patients with short-term mucosal healing had higher adalimumab concentrations at week 4 than those without (10.6 vs. $7.4 \mu \mathrm{g} /$ $\mathrm{mL}, p=0.014)$ [36]. In a retrospective multicenter study, including 98 IBD patients on adalimumab therapy, higher adalimumab concentrations during maintenance therapy were associated with objective therapeutic outcomes in IBD, including endoscopic, histologic, and composite remission [37]. Achieving adalimumab concentrations $\geq 12 \mu \mathrm{g} / \mathrm{mL}$ (OR: 8 ; 95\% CI: $2-31.9 ; p=0.003$ ) and $\geq 12.2$ $\mu \mathrm{g} / \mathrm{mL}$ (OR: 9.6; 95\% CI: 1.7-56.1; $p=0.012$ ) were independently associated with endoscopic and histologic remission in CD, respectively [37].

In a retrospective cohort study of 382 IBD patients (311 CD and $71 \mathrm{UC}$ ) on adalimumab, proactive TDM was compared to standard of care which consists of empirical dose escalation or reactive TDM. This study revealed that having at least one proactive TDM was independently associated with a reduced risk for treatment failure (hazard ratio: $0.4 ; p=0.022$ ) [38].

\section{Vedolizumab}

Data supporting the use of TDM with vedolizumab is not as robust as that with anti-TNF therapies. Increased vedolizumab drug clearance was found in patients with hypoalbuminemia and in those with an increased body weight [39]. Additionally, immunogenicity rates are low and the addition of immunomodulator agents does not affect vedolizumab clearance. It has been shown that high receptor saturation is achieved even with low-serum trough levels of vedolizumab [40]. Studies in UC (GEMINI 1) and CD patients (GEMINI-2 and GEMINI3) have demonstrated that high-serum vedolizumab levels are associated with improved outcomes during both induction and maintenance phases [41-50]. These results were more significant with quartile analyses and absolute increases in remission were stronger for UC rather than CD $[42,51]$. In GEMINI-I, patients in the highest quartile of vedolizumab levels at week 6 had higher remission rates than patients in the lowest quartile of vedolizumab levels [52]. Similarly, in GEMINI-2, patients in the highest quartile of vedolizumab levels at week 6 had higher clinical remission rates compared to patients in the lowest quartile of vedolizumab levels [53]. Specifically, higher vedolizumab trough levels, $>20 \mu \mathrm{g} / \mathrm{mL}$ at 6 weeks during the induction phase, showed an association with improved clinical outcomes [44, 48, 52-54]. As for maintenance concentrations, in a post hoc analysis of the GEMINI 1 study, UC patients who had higher vedolizumab level quartiles had greater deep remission rates at week 52 than patients who were in the lowest quartile [49, 55]. Guidi et al. [56] recently demonstrated in a prospective study of 101 patients with IBD (42 CD and 59 UC) that a vedolizumab level $>16.55 \mu \mathrm{g} / \mathrm{mL}$ at week 14 predicted treatment persistence during the first year of treatment.

Despite the available data supporting a correlation between high vedolizumab levels and improved clinical outcomes, using TDM for vedolizumab remains unclear, since immunogenicity with this drug is very low, and since therapeutic/target trough concentrations are still undetermined $[51,57,58]$. Based on a systemic review and meta-analysis, Singh et al. [55] proposed that if TDM is utilized, then a therapeutic target range for achieving clinical and/or endoscopic remission at week 6 would be between 20 and $30 \mu \mathrm{g} / \mathrm{mL}$, and a level between 12 and 20 $\mu \mathrm{g} / \mathrm{mL}$ for maintenance therapy. In a recently published article, experts agreed that target vedolizumab level at week 6 should be 33-37 $\mu \mathrm{g} / \mathrm{mL}$, while levels between 15 and $20 \mu \mathrm{g} / \mathrm{mL}$ should be achieved at week 14, after the induction period, and levels $10-15 \mu \mathrm{g} / \mathrm{mL}$ during maintenance in order to have improved clinical outcomes [59].

\section{Ustekinumab}

Similar to vedolizumab, there are limited data to guide TDM utilization, whether in the reactive or proactive setting, for patients receiving ustekinumab. In the initial trials of UC (UNIFI) and CD (UNITI-1, UNITI-2, and IMUNITI), when different doses of ustekinumab for induction and maintenance were compared, median drug concentrations were higher for patients achieving clinical response and remission [58, 60-62]. In the ustekinumab induction trials (UNITI-1 and UNITI-2), patients who
Shmais/Regueiro/Hashash 
Table 1. Summary of studies addressing TDM

\begin{tabular}{|c|c|c|c|c|c|c|c|}
\hline $\begin{array}{l}\text { Biological } \\
\text { agent }\end{array}$ & Reference & Study design & Disease & $\begin{array}{l}\text { Patients, } \\
n\end{array}$ & TDM timing & Outcome & $\begin{array}{l}\text { Favors } \\
\text { proactive }\end{array}$ \\
\hline \multirow[t]{7}{*}{ Infliximab } & Dreesen [22] & $\begin{array}{l}\text { RCT } \\
\text { (post hoc analysis) }\end{array}$ & $\mathrm{CD}$ & 122 & Proactive (week 2 and 6) & $\begin{array}{l}\text { Endoscopic remission at } \\
\text { week } 12\end{array}$ & Yes \\
\hline & Cornillie [23] & $\begin{array}{l}\text { RCT } \\
\text { (post hoc analysis) }\end{array}$ & $\mathrm{CD}$ & 385 & Proactive (week 14) & $\begin{array}{l}\text { Durable sustained long- } \\
\text { term response }\end{array}$ & Yes \\
\hline & Davidov [24] & Retrospective & $\begin{array}{l}\text { CD with } \\
\text { perianal fistula }\end{array}$ & 36 & $\begin{array}{l}\text { Proactive (Week } 2 \\
\text { and 6) }\end{array}$ & Perianal fistula response & Yes \\
\hline & Negoescu [19] & Simulated cohort & $\mathrm{CD}$ & & $\begin{array}{l}\text { Proactive (every } 6 \mathrm{mo} \text { ) } \\
\text { Reactive (only at flare) }\end{array}$ & Cost effectiveness & Yes \\
\hline & Shah [27] & SR and meta-analysi & $\mathrm{CD}$ and $\mathrm{UC}$ & 2,180 & Proactive versus reactive & $\begin{array}{l}\text { Failure to maintain clinical } \\
\text { remission }\end{array}$ & $\begin{array}{l}\text { Yes (low } \\
\text { quality of } \\
\text { evidence) }\end{array}$ \\
\hline & Fernandes [29] & Comparative study & $\mathrm{CD}$ and $\mathrm{UC}$ & 205 & $\begin{array}{l}\text { Proactive (at week } \\
14 \text { and before every } \\
2 \text { infusions) }\end{array}$ & $\begin{array}{l}\text { Need for surgery, } \\
\text { hospitalization, and } \\
\text { mucosal healing at } 2 \text {-year } \\
\text { follow-up }\end{array}$ & Yes \\
\hline & Liefferinckx [30] & Prospective & $\mathrm{CD}$ and $\mathrm{UC}$ & 63 & $\begin{array}{l}\text { Proactive (IFX peak } \\
\text { levels at week } 2 \text {, } \\
\text { intermediate levels at } \\
\text { week } 3 \text {, and trough } \\
\text { levels at week 6) }\end{array}$ & Remission at week 30 & Yes \\
\hline \multirow[t]{2}{*}{ Adalimumab } & Papamichael [35] & Retrospective & UC & 43 & Proactive (at week 4) & Short-term mucosal healing & Yes \\
\hline & Papamichael [37] & Retrospective & $\mathrm{CD}$ and $\mathrm{UC}$ & 382 & $\begin{array}{l}\text { Proactive (at least once) } \\
\text { versus SOC }\end{array}$ & $\begin{array}{l}\text { Reduced risk of treatment } \\
\text { failure }\end{array}$ & Yes \\
\hline \multirow[t]{3}{*}{ Vedolizumab } & Feagan [51] & RCT & UC & 225 & Proactive at week 6 & Clinical remission rates & - \\
\hline & Sandborn [52] & RCT & $\mathrm{CD}$ & 967 & Proactive at week 6 & Clinical remission rates & - \\
\hline & Guidi [55] & Prospective & $\mathrm{CD}$ and $\mathrm{UC}$ & 101 & $\begin{array}{l}\text { Proactive (at week } 6 \\
\text { and 14) }\end{array}$ & Sustained clinical benefit & Yes \\
\hline Ustekinumab & Verstockt [61] & Prospective & $\mathrm{CD}$ & 86 & Proactive (at week 8) & $\begin{array}{l}\text { Clinical remission and Fcal } \\
\text { level }\end{array}$ & \\
\hline
\end{tabular}

TDM, therapeutic drug monitoring; CD, Crohn's disease; UC, ulcerative colitis.

Table 2. Trough levels of the different biologicals from different studies evaluating TDM

\begin{tabular}{|c|c|c|c|}
\hline Drug & Timing & $\begin{array}{l}\text { Trough drug concentrations } \\
(\mu \mathrm{g} / \mathrm{mL}) \text { associated with } \\
\text { outcome's improvement }\end{array}$ & Outcome measure \\
\hline IFX & $\begin{array}{l}\text { Post-induction proactive TDM (week } 14)>7 \\
\text { Maintenance (? At } 1 \text { year) }\end{array}$ & $\begin{array}{l}>7 \\
>5\end{array}$ & $\begin{array}{l}\text { Increased likelihood of mucosal healing } \\
\text { Clinical/endoscopic remission }\end{array}$ \\
\hline $\mathrm{ADA}$ & $\begin{array}{l}\text { Post-induction proactive (week } 4 \text { ) >7 } \\
\text { Maintenance }\end{array}$ & $\begin{array}{l}>7 \\
\geq 5\end{array}$ & $\begin{array}{l}\text { Increased likelihood of mucosal healing } \\
\text { Clinical/endoscopic }\end{array}$ \\
\hline VDZ & $\begin{array}{l}\text { Induction (week 6) } \\
\text { Maintenance }\end{array}$ & $\begin{array}{l}>33-37 \\
>10-15\end{array}$ & $\begin{array}{l}\text { Clinical/endoscopic } \\
\text { Clinical/endoscopic }\end{array}$ \\
\hline UST & $\begin{array}{l}\text { Induction (week 8) } \\
\text { Maintenance }\end{array}$ & $\begin{array}{l}>3-7 \\
>1-3\end{array}$ & $\begin{array}{l}\text { Clinical } \\
\text { Clinical/endoscopic }\end{array}$ \\
\hline
\end{tabular}

TDM, therapeutic drug monitoring; ADA, anti-drug antibodies. 
were in the higher trough level quartiles at week 8 had higher rates of clinical remission than patients who had ustekinumab levels in the lower quartiles $[58,60]$. Also, during maintenance, more of the patients in with high quartile levels than low quartile levels were in clinical remission [61]. A recent prospective study on $86 \mathrm{CD}$ patients demonstrated that patients who had an ustekinumab trough level $\geq 4.2 \mu \mathrm{g} / \mathrm{mL}$ at week 8 had a $50 \%$ decrease in fecal calprotectin level [63]. In a recently published article, experts agreed that target ustekinumab level at week 8 should be $3-7 \mu \mathrm{g} / \mathrm{mL}$ while levels between 1 and $32 \mu \mathrm{g} /$ $\mathrm{mL}$ should be targeted during maintenance for both UC and CD patients [59].

Prospective studies are needed to define therapeutic trough levels for ustekinumab. Shukula et al. [40] suggest that ustekinumab level of $>4 \mu \mathrm{g} / \mathrm{mL}$ at week 8 and a level $>1-2 \mu \mathrm{g} / \mathrm{mL}$ during maintenance could be important to optimize IBD outcomes.

Table 1 summarizes the abovementioned studies and their outcomes. Table 2 displays the target.

\section{Gastroenterologists and TDM}

TDM-based therapeutic guidance is becoming widely used in routine practice, particularly in patients with LOR or those who develop infusion reactions. A survey study of 403 gastroenterologists in the United States regarding the use and the barriers toward TDM showed that the majority use reactive TDM for secondary and primary LOR, while only $36.6 \%$ use TDM proactively [64]. The greatest barriers to TDM implementation were uncertainty about insurance coverage (77.9\%), high out-ofpocket patient costs $(76.4 \%)$, and time lag from serum sample to result (38.5\%) [64].

\section{Conclusion}

TDM is a valuable tool used by gastroenterologists to aid in optimizing IBD therapies. Reactive TDM is widely accepted in IBD patients with suspected LOR, especially in those receiving anti-TNF agents. Reactive TDM for the newer biologicals (ustekinumab and vedolizumab) is also acceptable, although the immunogenicity rates of these drugs are very low and the therapeutic drug levels have not been clearly defined. Proactive TDM is emerging as a reasonable approach to patients initiated on anti-TNF therapy, specifically infliximab and, to some extent, adalimumab. For example, post-induction TDM for inflix- imab and adalimumab in patients with severe UC and fistulizing CD may improve outcomes and optimize therapeutic levels of drug. Similarly, TDM may play a role in patients considering de-escalation from combination with a thiopurine. In this scenario, checking levels of anti-TNF prior to and after stopping the concomitant immunomodulator is a reasonable strategy. To date, proactive TDM is not widely applied to ustekinumab and vedolizumab and more data are required before this becomes part of clinical practice.

\section{Statement of Ethics}

The presented work is a review article and has not directly dealt with human or animal research; therefore, no informed consent was obtained.

\section{Conflict of Interest Statement}

The authors have no conflicts of interest to declare.

\section{Funding Sources}

The authors received no funding.

\section{Author Contributions}

M. Shmais contributed to the data collection and drafting of the manuscript. M. Regueiro contributed to critical review of the manuscript for important intellectual content and final approval of the version to be published. J.G. Hashash contributed to the data collection, drafting of the manuscript, critical review of the manuscript, and final approval of the version to be published.
1 Colombel JF, Narula N, Peyrin-Biroulet L. Management strategies to improve outcomes of patients with inflammatory bowel diseases. Gastroenterology. 2017;152(2):351-61.e5.

2 Papamichael K, Cheifetz AS, Melmed GY, Irving PM, Vande Casteele N, Kozuch PL, et al. Appropriate therapeutic drug monitoring of biologic agents for patients with inflammatory bowel diseases. Clin Gastroenterol Hepatol. 2019;17(9):1655-68.e3.

3 Casteele NV. Assays for measurement of TNF antagonists in practice. Frontline Gastroenterol. 2017;8(4):236-42.

4 Khanna R, Levesque BG, Sandborn WJ, Feagan BG. Therapeutic drug monitoring of TNF antagonists in inflammatory bowel disease. Gastroenterol Hepatol. 2014;10(8):478.
Shmais/Regueiro/Hashash 
5 Casteele NV, Herfarth H, Katz J, Falck-Ytter Y, Singh S. American Gastroenterological Association Institute technical review on the role of therapeutic drug monitoring in the management of inflammatory bowel diseases. Gastroenterology. 2017;153(3):835-57.e6.

6 Paul S, Del Tedesco E, Marotte H, RinaudoGaujous M, Moreau A, Phelip JM, et al. Therapeutic drug monitoring of infliximab and mucosal healing in inflammatory bowel disease: a prospective study. Inflamm Bowel Dis. 2013;19(12):2568-76.

7 Yanai H, Lichtenstein L, Assa A, Mazor Y, Weiss B, Levine A, et al. Levels of drug and antidrug antibodies are associated with outcome of interventions after loss of response to infliximab or adalimumab. Clin Gastroenterol Hepatol. 2015;13(3):522-30.e2.

8 Roblin X, Marotte H, Rinaudo M, Del Tedesco E, Moreau A, Phelip JM, et al. Association between pharmacokinetics of adalimumab and mucosal healing in patients with inflammatory bowel diseases. Clin Gastroenterol Hepatol. 2014;12(1):80-4.e2.

9 Bendtzen K, Ainsworth M, Steenholdt C, Thomsen OØ, Brynskov J. Individual medicine in inflammatory bowel disease: monitoring bioavailability, pharmacokinetics and immunogenicity of anti-tumour necrosis factoralpha antibodies. Scand J Gastroenterol. 2009; 44(7):774-81.

10 Feuerstein JD, Nguyen GC, Kupfer SS, FalckYtter Y, Singh S, Gerson L, et al. American Gastroenterological Association Institute guideline on therapeutic drug monitoring in inflammatory bowel disease. Gastroenterology. 2017;153(3):827-34.

11 Rubin DT, Ananthakrishnan AN, Siegel CA, Sauer BG, Long MD. ACG clinical guideline: ulcerative colitis in adults. Am J Gastroenterol. 2019;114(3):384-413.

12 Torres J, Bonovas S, Doherty G, Kucharzik T, Gisbert JP, Raine T, et al. ECCO guidelines on therapeutics in Crohn's disease: medical treatment. J Crohns Colitis. 2020;14(1):4-22.

13 Mitrev N, Vande Casteele N, Seow CH, Andrews JM, Connor SJ, Moore GT, et al. Review article: consensus statements on therapeutic drug monitoring of anti-tumour necrosis factor therapy in inflammatory bowel diseases. Aliment Pharmacol Ther. 2017;46(11-12): 1037-53.

14 Lamb CA, Kennedy NA, Raine T, Hendy PA, Smith PJ, Limdi JK, et al. British Society of Gastroenterology consensus guidelines on the management of inflammatory bowel disease in adults. Gut. 2019 Dec;68(Suppl 3):s1106.

15 Kamperidis N, Middleton P, Tyrrell T, Stasinos I, Arebi N. Impact of therapeutic drug level monitoring on outcomes of patients with Crohn's disease treated with infliximab: real world data from a retrospective single centre cohort study. Frontline Gastroenterol. 2019;10(4):330-6.

16 Gisbert JP, Panés J. Loss of response and requirement of infliximab dose intensification in Crohn's disease: a review. Am J Gastroenterol. 2009;104(3):760-7.

17 Ben-Horin S, Chowers Y. Review article: loss of response to anti-TNF treatments in Crohn's disease. Aliment Pharmacol Ther. 2011;33(9):987-95.

18 Billioud V, Sandborn WJ, Peyrin-Biroulet L. Loss of response and need for adalimumab dose intensification in Crohn's disease: a systematic review. Am J Gastroenterol. 2011; 106(4):674-84.

19 Negoescu DM, Enns EA, Swanhorst B, Baumgartner B, Campbell JP, Osterman MT, et al. Proactive vs reactive therapeutic drug monitoring of infliximab in Crohn's disease: a cost-effectiveness analysis in a simulated cohort. Inflamm Bowel Dis. 2020;26(1):103-11.

20 Papamichael K, Vajravelu RK, Vaughn BP, Osterman MT, Cheifetz AS. Proactive infliximab monitoring following reactive testing is associated with better clinical outcomes than reactive testing alone in patients with inflammatory bowel disease. J Crohns Colitis. 2018; 12(7):804-10.

21 D'Haens G, Vermeire S, Lambrecht G, Baert $F$, Bossuyt P, Pariente B, et al. Increasing infliximab dose based on symptoms, biomarkers, and serum drug concentrations does not increase clinical, endoscopic, and corticosteroid-free remission in patients with active luminal Crohn's disease. Gastroenterology. 2018;154(5):1343-51.e1.

22 Dreesen E, Baert F, Laharie D, Bossuyt P, Bouhnik Y, Buisson A, et al. Monitoring a combination of calprotectin and infliximab identifies patients with mucosal healing of Crohn's disease. Clin Gastroenterol Hepatol. 2020;18(3):637-46.e11

23 Cornillie F, Hanauer SB, Diamond RH, Wang J, Tang KL, Xu Z, et al. Postinduction serum infliximab trough level and decrease of C-reactive protein level are associated with durable sustained response to infliximab: a retrospective analysis of the ACCENT I trial. Gut. 2014;63(11):1721-7.

24 Davidov Y, Ungar B, Bar-Yoseph H, Carter D, Haj-Natour O, Yavzori M, et al. Association of induction infliximab levels with clinical response in perianal Crohn's disease. J Crohns Colitis. 2017;11(5):549-55.

25 Strik AS, Löwenberg M, Mould DR, Berends SE, Ponsioen CI, van den Brande JMH, et al. Efficacy of dashboard driven dosing of infliximab in inflammatory bowel disease patients; a randomized controlled trial. Scand J Gastroenterol. 2021;56:145-54.

26 Vaughn BP, Martinez-Vazquez M, Patwardhan VR, Moss AC, Sandborn WJ, Cheifetz AS. Proactive therapeutic concentration monitoring of infliximab may improve outcomes for patients with inflammatory bowel disease: results from a pilot observational study. Inflamm Bowel Dis. 2014;20(11):1996-2003.

27 Shah R, Hoffman GR, El-Dallal M, Goldowsky AM, Chen Y, Feuerstein JD. Is therapeutic drug monitoring for anti-tumour necrosis factor agents in adults with inflamma- tory bowel disease ready for standard of care? A systematic review and meta-analysis. J Crohns Colitis. 2020;14(8):1057-65.

28 Casteele NV, Ferrante M, Van Assche G, Ballet V, Compernolle G, Van Steen K, et al. Trough concentrations of infliximab guide dosing for patients with inflammatory bowel disease. Gastroenterology. 2015;148(7):1320-9.e3.

29 Fernandes SR, Bernardo S, Simões C, Gonçalves AR, Valente A, Baldaia C, et al. Proactive infliximab drug monitoring is superior to conventional management in inflammatory bowel disease. Inflamm Bowel Dis. 2020; 26(2):263-70.

30 Liefferinckx C, Bottieau J, Toubeau J-F, Thomas D, Rahier J-F, Louis E, et al. Collecting new peak and intermediate infliximab levels to predict remission in inflammatory bowel diseases. Inflamm Bowel Dis. 2021. Epub ahead of print.

31 West RL, Zelinkova Z, Wolbink GJ, Kuipers EJ, Stokkers PC, Van Der Woude CJ. Immunogenicity negatively influences the outcome of adalimumab treatment in Crohn's disease. Aliment Pharmacol Ther. 2008;28(9):1122-6.

32 Ungar B, Engel T, Yablecovitch D, Lahat A, Lang A, Avidan B, et al. Prospective observational evaluation of time-dependency of adalimumab immunogenicity and drug concentrations: the POETIC study. Am J Gastroenterol. 2018;113(6):890-8.

33 Paul S, Moreau AC, Del Tedesco E, Rinaudo M, Phelip JM, Genin C, et al. Pharmacokinetics of adalimumab in inflammatory bowel diseases: a systematic review and meta-analysis. Inflamm Bowel Dis. 2014;20(7):1288-95.

34 Verstockt B, Moors G, Bian S, Van Stappen T, Van Assche G, Vermeire S, et al. Influence of early adalimumab serum levels on immunogenicity and long-term outcome of anti-TNF naive Crohn's disease patients: the usefulness of rapid testing. Aliment Pharmacol Ther. 2018;48(7):731-9.

35 Chiu YL, Rubin DT, Vermeire S, Louis E, Robinson AM, Lomax KG, et al. Serum adalimumab concentration and clinical remission in patients with Crohn's disease. Inflamm Bowel Dis. 2013;19(6):1112-22.

36 Papamichael K, Baert F, Tops S, Assche GV, Rutgeerts P, Vermeire S, et al. Post-induction adalimumab concentration is associated with short-term mucosal healing in patients with ulcerative colitis. J Crohns Colitis. 2017;11(1): 53-9.

37 Juncadella A, Papamichael K, Vaughn BP, Cheifetz AS. Maintenance adalimumab concentrations are associated with biochemical, endoscopic, and histologic remission in inflammatory bowel disease. Dig Dis Sci. 2018; 63(11):3067-73.

38 Papamichael K, Juncadella A, Wong D, Rakowsky S, Sattler LA, Campbell JP, et al. Proactive therapeutic drug monitoring of adalimumab is associated with better long-term outcomes compared with standard of care in patients with inflammatory bowel disease. Crohns Colitis. 2019;13(8):976-81. 
39 Steenholdt C, Bendtzen K, Brynskov J, Ainsworth MA. Optimizing treatment with TNF inhibitors in inflammatory bowel disease by monitoring drug levels and antidrug antibodies. Inflamm Bowel Dis. 2016;22(8):19992015.

40 Shukla R, Ananthakrishnan A. Therapeutic drug monitoring of non-anti-tumor necrosis factor biologics. Clin Gastroenterol Hepatol. 2021;19:1108-10.

41 Ungar B, Kopylov U, Yavzori M, Fudim E, Picard O, Lahat A, et al. Association of vedolizumab level, anti-drug antibodies, and a $4 \beta 7$ occupancy with response in patients with inflammatory bowel diseases. Clin Gastroenterol Hepatol. 2018;16(5):697-705.e7.

42 Rosario M, French JL, Dirks NL, Sankoh S, Parikh A, Yang H, et al. Exposure-efficacy relationships for vedolizumab induction therapy in patients with ulcerative colitis or Crohn's disease. J Crohns Colitis. 2017;11(8): 921-9.

43 Liefferinckx C, Minsart C, Cremer A, Amininejad L, Tafciu V, Quertinmont E, et al. Early vedolizumab trough levels at induction in inflammatory bowel disease patients with treatment failure during maintenance. Eur J Gastroenterol Hepatol. 2019;31(4):478-85.

44 Yacoub W, Williet N, Pouillon L, Di-Bernado T, De Carvalho Bittencourt M, Nancey S, et al. Early vedolizumab trough levels predict mucosal healing in inflammatory bowel disease: a multicentre prospective observational study. Aliment Pharmacol Ther. 2018;47(7): 906-12.

45 Dreesen E, Verstockt B, Bian S, de Bruyn M, Compernolle G, Tops S, et al. Evidence to support monitoring of vedolizumab trough concentrations in patients with inflammatory bowel diseases. Clin Gastroenterol Hepatol. 2018;16(12):1937-46.e8

46 Pouillon L, Rousseau H, Busby-Venner H, De Carvalho Bittencourt M, Choukour M, Gauchotte G, et al. Vedolizumab trough levels and histological healing during maintenance therapy in ulcerative colitis. J Crohns Colitis. 2019;13(8):970-5.

47 Buer LCT, Moum BA, Cvancarova M, Warren DJ, Bolstad N, Medhus AW, et al. Real world data on effectiveness, safety and thera- peutic drug monitoring of vedolizumab in patients with inflammatory bowel disease. A single center cohort. Scand J Gastroenterol. 2019;54(1):41-8.

48 Williet N, Boschetti G, Fovet M, Di Bernado T, Claudez P, Del Tedesco E, et al. Association between low trough levels of vedolizumab during induction therapy for inflammatory bowel diseases and need for additional doses within 6 months. Clin Gastroenterol Hepatol. 2017;15(11):1750-7.e3.

49 Sandborn WJ, Colombel JF, Panaccione R, Dulai PS, Rosario M, Cao C, et al. Deep remission with vedolizumab in patients with moderately to severely active ulcerative colitis: a GEMINI 1 post hoc analysis. J Crohns Colitis. 2019;13(2):172-81.

50 Osterman MT, Rosario M, Lasch K, Barocas M, Wilbur JD, Dirks NL, et al. Vedolizumab exposure levels and clinical outcomes in ulcerative colitis: determining the potential for dose optimisation. Aliment Pharmacol Ther. 2019;49(4):408-18.

51 Ward MG, Sparrow MP, Roblin X. Therapeutic drug monitoring of vedolizumab in inflammatory bowel disease: current data and future directions. Therap Adv Gastroenterol. 2018;11:1756284818772786.

52 Feagan BG, Rutgeerts P, Sands BE, Hanauer S, Colombel JF, Sandborn WJ, et al. Vedolizumab as induction and maintenance therapy for ulcerative colitis. N Engl J Med. 2013; 369(8):699-710.

53 Sandborn WJ, Feagan BG, Rutgeerts P, Hanauer S, Colombel JF, Sands BE, et al. Vedolizumab as induction and maintenance therapy for Crohn's disease. N Engl J Med. 2013;369(8):711-21.

54 Osterman MT, Roblin X, Glover SC, Navaneethan U, Popa MA, Wyant T, et al. 512 Association of vedolizumab drug concentrations at or before week 6 with remission at week 14 in moderately to severely active ulcerative colitis patients from GEMINI 1. Gastroenterology. 2016;150(4):S105.

55 Singh S, Dulai PS, Vande Casteele N, Battat R, Fumery M, Boland BS, et al. Systematic review with meta-analysis: association between vedolizumab trough concentration and clinical outcomes in patients with inflammatory bow- el diseases. Aliment Pharmacol Ther. 2019; 50(8):848-57.

56 Guidi L, Pugliese D, Panici Tonucci T, Bertani L, Costa F, Privitera G, et al. Early vedolizum$\mathrm{ab}$ trough levels predict treatment persistence over the first year in inflammatory bowel disease. United European Gastroenterol J. 2019; 7(9):1189-97.

57 Seinen ML, De Boer NK, van Bodegraven AA. Key insights from therapeutic drug monitoring in Crohn's disease patients. Expert Opin Drug Metab Toxicol. 2019;15(5):399-406.

58 Lee SD, Shivashankar R, Quirk D, Zhang H, Telliez JB, Andrews J, et al. Therapeutic drug monitoring for current and investigational inflammatory bowel disease treatments. J Clin Gastroenterol. 2021;55(3):195.

59 Restellini S, Afif W. Update on TDM (therapeutic drug monitoring) with ustekinumab, vedolizumab and tofacitinib in inflammatory bowel disease. J Clin Med. 2021;10(6):1242.

60 Feagan BG, Sandborn WJ, Gasink C, Jacobstein D, Lang $\mathrm{Y}$, Friedman JR, et al. Ustekinumab as induction and maintenance therapy for Crohn's disease. N Engl J Med. 2016;375(20):1946-60.

61 Adedokun OJ, Xu Z, Gasink C, Jacobstein D, Szapary P, Johanns J, et al. Pharmacokinetics and exposure response relationships of ustekinumab in patients with Crohn's disease. Gastroenterology. 2018;154(6):1660-71.

62 Battat R, Kopylov U, Bessissow T, Bitton A, Cohen A, Jain A, et al. Association between ustekinumab trough concentrations and clinical, biomarker, and endoscopic outcomes in patients with Crohn's disease. Clin Gastroenterol Hepatol. 2017;15(9):1427-34e2.

63 Verstockt B, Dreesen E, Noman M, Outtier A, Van den Berghe N, Aerden I, et al. Ustekinumab Exposure-outcome analysis in Crohn's disease only in part explains limited endoscopic remission rates. J Crohns Colitis. 2019;13(7): 864-72.

64 Grossberg LB, Papamichael K, Feuerstein JD, Siegel CA, Ullman TA, Cheifetz AS. A survey study of gastroenterologists' attitudes and barriers toward therapeutic drug monitoring of anti-TNF therapy in inflammatory bowel disease. Inflamm Bowel Dis. 2018;24(1):191-7. 